\title{
Comparison of general obesity and measures of body fat distribution in older adults in relation to cancer risk: meta-analysis of individual participant data of seven prospective cohorts in Europe
}

Heinz Freisling ${ }^{\star}, 1$, Melina Arnold ${ }^{2}$, Isabelle Soerjomataram² ${ }^{2}$, Mark George O’Doherty ${ }^{3}$, José Manuel Ordóñez-Mena ${ }^{4,5,6}$, Christina Bamia ${ }^{7,8}$, Ellen Kampman ${ }^{9}$, Michael Leitzmann ${ }^{10}$, Isabelle Romieu ${ }^{1}$, Frank Kee ${ }^{3}$, Konstantinos Tsilidis ${ }^{7,11,12}$, Anne Tjønneland ${ }^{13}$, Antonia Trichopoulou, 7, , Paolo Boffetta ${ }^{7,14}$, Vassiliki Benetou ${ }^{7,8}, \mathrm{H}$ B(as) Bueno-de-Mesquita ${ }^{12,15,16}$, José María Huerta ${ }^{17,18}$, Hermann Brenner ${ }^{5,19,20}$, Tom Wilsgaard ${ }^{21}$ and Mazda Jenab ${ }^{1}$

Background: We evaluated the associations of anthropometric indicators of general obesity (body mass index, BMI), an established risk factor of various cancer, and body fat distribution (waist circumference, WC; hip circumference, HC; and waist-tohip ratio, WHR), which may better reflect metabolic complications of obesity, with total obesity-related and site-specific (colorectal and postmenopausal breast) cancer incidence.

Methods: This is a meta-analysis of seven prospective cohort studies participating in the CHANCES consortium including 18668 men and 24751 women with a mean age of 62 and 63 years, respectively. Harmonised individual participant data from all seven cohorts were analysed separately and alternatively for each anthropometric indicator using multivariable Cox proportional hazards models.

Results: After a median follow-up period of 12 years, 1656 first-incident obesity-related cancers (defined as postmenopausal female breast, colorectum, lower oesophagus, cardia stomach, liver, gallbladder, pancreas, endometrium, ovary, and kidney) had occurred in men and women. In the meta-analysis of all studies, associations between indicators of adiposity, per s.d. increment, and risk for all obesity-related cancers combined yielded the following summary hazard ratios: $1.11(95 \% \mathrm{Cl} 1.02-1.21)$ for BMI, 1.13 (95\% Cl 1.04-1.23) for WC, 1.09 (95\% Cl 0.98-1.21) for HC, and 1.15 (95\% Cl 1.00-1.32) for WHR. Increases in risk for colorectal cancer were $16 \%, 21 \%, 15 \%$, and $20 \%$, respectively per s.d. of BMI, WC, HC, and WHR. Effect modification by hormone therapy $(H T)$ use was observed for postmenopausal breast cancer $\left(P_{\text {interaction }}<0.001\right)$, where never HT users showed an $\sim 20 \%$ increased risk per s.d. of BMI, WC, and HC compared to ever users.

Conclusions: BMI, WC, HC, and WHR show comparable positive associations with obesity-related cancers combined and with colorectal cancer in older adults. For postmenopausal breast cancer we report evidence for effect modification by HT use.

*Correspondence: Dr H Freisling; E-mail: freislingh@iarc.fr

Received 12 November 2016; revised 3 March 2017; accepted 27 March 2017; published online 25 April 2017

(C) 2017 Cancer Research UK. All rights reserved 0007-0920/17 
The proportion of overweight (body mass index, BMI $\left.>25 \mathrm{~kg} \mathrm{~m}^{-2}\right)$ or obese $\left(\mathrm{BMI}>30 \mathrm{~kg} \mathrm{~m}^{-2}\right)$ adults worldwide increased substantially between 1980 and 2013 (NCD Risk Factor Collaboration, 2016), with parallel increases in children and adolescents ( $\mathrm{Ng}$ et al, 2014). Obesity prevalence reaches its peak between the age of 55 and 60 years in men with $\sim 25 \%$ being obese in high-income countries and about 5 years later in women with $\sim 30 \%$ being obese ( $\mathrm{Ng}$ et al, 2014). This may have substantial implications for risk of subsequent cancer development, particularly in older adults $(60+$ years $)$ considering that they are the fastest growing demographic group in most high-income countries.

It is well established that a high BMI is associated with an increased risk of a large number of non-communicable diseases, including cancer. Excess body fatness, as defined by high BMI, has been convincingly linked to an increased risk of eleven different cancer types, including cancer of the oesophagus (adenocarcinoma), gastric cardia, colorectum (CRC, colorectal cancer), gallbladder, pancreas, liver, breast (postmenopausal), ovary, endometrium, kidney and prostate (advanced stage; World Cancer Research Fund/American Institute for Cancer Research, 2007; Renehan et al, 2008; Bhaskaran et al, 2014). An updated IARC consensus review also judged the strength of evidence sufficient for thyroid, meningioma, and multiple myeloma (LaubySecretan et al, 2016). These cancers alone comprise about $50 \%$ of the total global burden of cancer (based on GLOBOCAN 2012 data; Arnold et al, 2016b).

However, there are uncertainties with regard to how well BMI captures the complex biology underlying associations between adiposity and cancer risk (Renehan et al, 2015). This is relevant to the development of cancer prevention strategies because it is increasingly recognised that a proportion of overweight or obese individuals - as defined by a high BMI - might not be at an increased risk for metabolic complications of obesity and its consequences such as cancer (Renehan et al, 2015). Waist circumference (WC) and waist-to-hip ratio (WHR) are therefore often used in epidemiological and clinical settings as a means of quantifying body fat distribution indicating central adiposity (National Heart, Lung and BI, 1998; Hu, 2008), and they are thought to be superior predictors of risk of cancer development, at least for the colon and postmenopausal breast (Moore et al, 2004; Pischon et al, 2006; White et al, 2015). Moreover, a greater hip circumference (HC), after controlling for WC and/or BMI, may be associated with reduced risks of coronary heart disease, type 2 diabetes, and mortality (Heitmann and Lissner, 2011; Cameron et al, 2013), but its relation to cancer risk has been fully explored in only a few recent studies (Keimling et al, 2013; Steffen et al, 2015), where either no association was found for risk of colon cancer with and without adjustment for BMI (Keimling et al, 2013) or inverse associations with risk of oesophageal adenocarcinoma after adjustment for WC (Steffen et al, 2015). Strictly speaking, HC is not a measure of central adiposity, but of fat accumulated in the lower part of the body (such as the hips and thighs; $\mathrm{Hu}, 2008$ ). Together, the evidence that measures of body fat distribution or central adiposity are better predictors of cancer risk than BMI is inconsistent. Also, only a few prospective studies comparing different measures of adiposity were carried out in adults aged 60 years and above.

Our primary objective was to derive standardised risk estimates for anthropometric measures of general adiposity (BMI) and body fat distribution (WC, HC, and WHR) and their association with 'obesity-related' cancers combined (i.e., cancer sites with convincing evidence of a positive association with greater body fatness) as well as CRC and (postmenopausal) breast cancer in a large population of older adults from Europe. Secondary objectives were to examine the shape of the dose-response relationships and to evaluate potential effect modification by sex, smoking status, use of hormone therapy (HT), and interaction between measures of body fat distribution and general adiposity.

\section{MATERIALS AND METHODS}

Study population. The Consortium on Health and Ageing: Network of Cohorts in Europe and the United States (CHANCES) project is a multi-country study, which aims to harmonise the data from ongoing prospective cohort studies in Europe and North America (Boffetta et al, 2014).

The following CHANCES cohorts provided the data for the current analysis: the study centres in Denmark, Greece, The Netherlands, and Spain of EPIC Elderly, which is a subset of the European Prospective Investigation into Cancer and Nutrition (EPIC) project that consists of participants aged 60 years or older at recruitment; the Epidemiological Study on Chances for Prevention, Early Detection, and Optimized THERapy of Chronic Diseases at Old Age (ESTHER), a population-based cohort covering the entire federal state of Saarland in Germany, aged 50 or older at recruitment; the PRIME Belfast study, which is a cohort of male residents aged 50-60 years of Belfast and the surrounding area in the United Kingdom; and the Tromsø study, which recruited men and women in Norway between 1994 and 1995 (4th wave) aged 50-84 years. Other CHANCES cohorts either decided not to participate in this analysis or could not provide cancer incidence data. The participating cohorts' key characteristics are summarised in Table 1. Additional information on the individual cohorts has been given previously (Boffetta et al, 2014). We followed similar inclusion and exclusion criteria, which are displayed in Figure 1, as in a companion paper on overweight duration and risk of cancer (Arnold et al, 2016a). Further to the exclusions shown in Figure 1, we excluded participants with an implausible BMI below 15 or above $45 \mathrm{~kg} \mathrm{~m}^{-2}$ from the analysis.

All CHANCES cohort studies are conducted in accordance with the Declaration of Helsinki. For each study, investigators satisfied the local requirements for ethical research, including obtaining informed consent from participants.

Outcomes. Incident cancer cases were identified through linkage to cancer registries (EPIC Netherlands, EPIC Denmark, Tromsø) or through self-reports that were confirmed by medical records and/or pathology reports (ESTHER, PRIME Belfast) or both (EPIC Spain, EPIC Greece). All analyses were conducted for cancer sites with convincing evidence of a positive association with greater body fatness (World Cancer Research Fund/American Institute for Cancer Research, 2007; Renehan et al, 2008; Lauby-Secretan et al, 2016). We examined first invasive breast cancer (ICD-O-3 C50) at postmenopausal ages, CRC (C18-21), and the combination of the two in conjunction with 'other obesity-related cancers' that included cancer of the lower oesophagus (C15.5, as a proxy for oesophageal adenocarcinoma in the absence of histological data), gastric cardia (C16.0), liver (C22), gallbladder (C23), pancreas (C25), endometrium (C54), ovary (C56) and kidney (C64), together labelled as 'obesity-related cancers'. Advanced prostate cancer was not included because we lacked information on tumour stage. Also, thyroid, meningioma, and multiple myeloma (LaubySecretan et al, 2016) were not included due to very small numbers of incident cases and inconsistencies in the available data across cohorts. Small numbers precluded the possibility of performing separate analyses of each obesity-related cancer site.

Anthropometric assessment. In all cohorts except ESTHER, height and weight were measured by trained personnel at baseline. In the ESTHER cohort, height and weight were self-reported by the study participants.

Waist and hip circumference were measured by trained personnel in all cohorts except ESTHER, where these measures were not assessed; the narrowest torso circumference (natural waist) or midway between the lowest rib and iliac crest was used for the waist measurement, while the widest circumference or 
Table 1. Study and participants characteristics by cohort in the CHANCES consortium of middle-aged and older adults

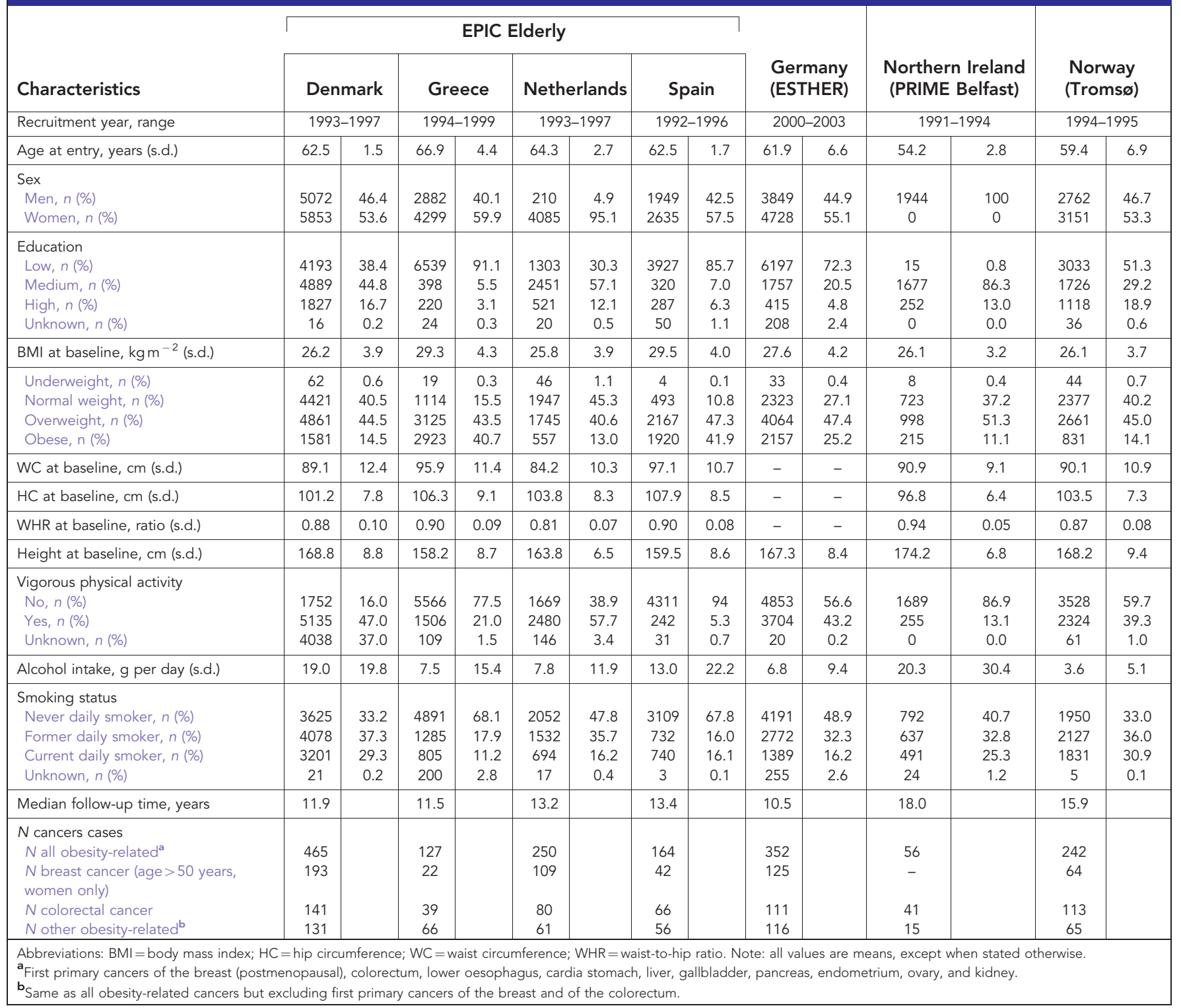

maximum circumference over the buttocks was used for the hip measurement. The majority of cohorts reported that participants were asked to remove any heavy outer garments (light clothing or underwear only allowed) for the anthropometric measurements.

Covariate assessment. Age, sex, smoking status, physical activity, alcohol consumption, and HT use in women were collected in all cohorts following standardised procedures and a posteriori harmonised within the CHANCES project (Boffetta et al, 2014). All covariates except alcohol consumption (continuous, g per day) were modelled categorically: (daily) smoking status (never daily smoker; former daily smoker; current daily smoker; unknown), (vigorous) physical activity (yes; no; unknown) defined according to the CHANCES harmonisation rules as 'performing intense exercise at least once a week', level of education attained (primary or less; more than primary but less than college or university; college or university; unknown), current use (or history) of HT in women (ever; never; unknown).

Statistical analysis. Cox proportional hazard models with age as the time metric were used to estimate hazard ratios (HR) and 95\% confidence intervals (CI) for the relation between four obesity indicators and the risk of developing (1) 'obesity-related cancers', (2) CRC, (3) postmenopausal breast cancer, and (4) 'other obesityrelated cancers' in each of the included cohorts. All obesity indicators were treated as continuous covariates; BMI was examined as a measure of overall adiposity, whereas WC, HC, and WHR were examined as measures of body fat distribution. For comparability between the four obesity indicators, we calculated the HR and their CI per 1-s.d. increment of each indicator (Keimling et al, 2013). The relationships between anthropometric measures were evaluated using Pearson correlation coefficients (Supplementary Table S1).

Subjects were censored at age of study exit (death, lost to followup, any cancer diagnosis other than cancers considered as outcomes in this study, and end of follow-up), whichever occurred first.

For all outcomes, three models with different sets of adjustments were fitted. Model 1 included each of the anthropometric measures alternatively, stratified by age (1-year categories) and sex, and adjusted for height. Model 2 (main model) extended Model 1 by further adjusting for smoking status, alcohol consumption, level of educational attainment, physical activity, and recruitment year. Missing values in any of the categorical covariates were included as 


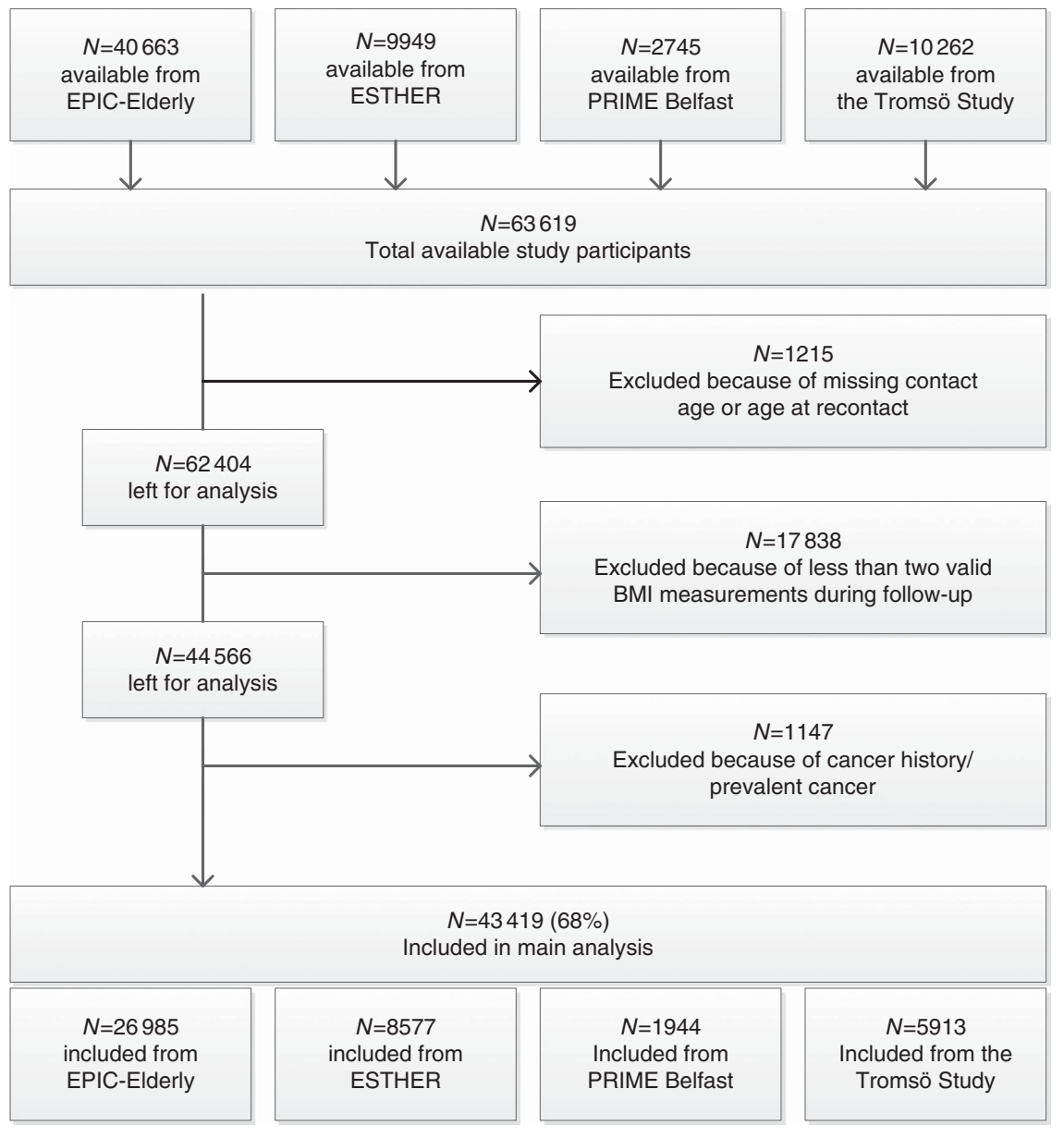

Figure 1. Flowchart of participant inclusion.

a separate category. Model 3 was based as model 2, but with mutual adjustment for all anthropometric measures using residuals of WC, HC, and WHR (Roswall et al, 2014).

All Cox models were fitted for each study separately (EPIC Elderly was sub-divided into study centres/countries) giving a study-level risk per 1-s.d. increment and the results of models 2 and 3 were then combined using DerSimonian and Laird randomeffect meta-analysis (Harris et al, 2008). The heterogeneity of associations across studies was expressed by $I^{2}$ (Higgins and Thompson, 2002).

The proportional hazard assumptions in the study-specific analysis were assessed by visual inspection of log-log plots and by statistical tests using Schoenfeld residuals. Because the proportional hazards were unlikely for sex and age, we stratified Cox models by sex and age (in 1-year categories). Exclusion of individuals with missing data on smoking, education or physical activity gave virtually the same results.

To directly compare cancer risk discrimination between the four obesity indicators, we used respective predictions from Cox models (model 2, pooling all cohorts) to assess discrimination by Harrell's C-index (Fibrinogen Studies Collaboration, 2009).

For analyses addressing the impact of effect modification, we pooled all cohorts into one dataset, and additionally stratified all Cox models by study. To investigate potential non-linear doseresponse associations between the four obesity indicators and cancer risks, we used three-knot restricted cubic spline models at Harrell's default percentiles (i.e., 10th, 50th, and 90th) in combination with a Wald-type test to evaluate the linearity hypothesis (Orsini and Greenland, 2011).
We tested a priori for potential interactions between the four adiposity indicators and for effect modification of the studied associations by smoking status and HT use, and between measures of body fat distribution and general adiposity, using likelihood ratio tests. Since Cox models were stratified by sex and age, no formal tests for interaction by sex or age were performed.

All statistical tests were two-sided and $P$-values were considered statistically significant at the 0.05 level. All statistical analyses were performed using Stata 12.1 (College Station, TX, USA).

\section{RESULTS}

In total, 43419 participants were included in this study, with 1656 obesity-related cancer cases occurring during a median follow-up time of 12 years, which ranged between 10.4 years in Germany (ESTHER) and 18.0 years in Northern Ireland (PRIME Belfast) (Table 1). Study participants were recruited between 1991 and 2003, with a mean age at study entry ranging from 54 years in Northern Ireland to 67 years in Greece (EPIC Greece). The prevalence of obesity $\left(\mathrm{BMI}>30 \mathrm{~kg} \mathrm{~m}^{-2}\right)$ at recruitment was lowest in Northern Ireland with $11 \%$ and highest in participants from Spain with $42 \%$.

Meta-analysis of adiposity measures and risk of cancer. In the meta-analysis of all studies, BMI, WC, and WHR were significantly associated with an increased risk of 'obesity-related cancers'; the HRs per 1-s.d. increment in BMI, WC, and WHR were $1.11(95 \%$ CI: $1.02-1.21), 1.13$ (95\% CI: 1.04-1.23), and 1.15 (95\% CI: 
$1.00-1.32)$, respectively. For BMI, the risk was most pronounced in the PRIME Belfast study ( $\mathrm{HR}=1.50,95 \% \mathrm{CI}: 1.08-2.07)$ and a statistically non-significant inverse association was observed in the EPIC Spain cohort (HR $=0.88,95 \%$ CI: 0.74-1.04; Figure 2). After adjusting for HC and WC (Model 3-Supplementary Figure S1), the HR for EPIC Spain per 1-s.d. increase in BMI changed to 1.14 (95\% CI: $0.82-1.60)$ and heterogeneity across studies for BMI decreased from $59 \% \quad\left(P_{\text {heterogeneity }}=0.02\right) \quad$ to $\quad<1 \%$ $\left(P_{\text {heterogeneity }}=0.58\right)$. Omitting EPIC Spain from the meta-analysis also reduced heterogeneity for BMI (to $25 \%, P_{\text {heterogeneity }}=0.25$ ) and for $\mathrm{HC}$ (61 to $7 \%, P_{\text {heterogeneity }}=0.369$ ). HC was positively associated with risk of 'obesity-related cancers' with a comparable effect size $\left(\mathrm{HR}_{1-\text { s.d. increase }}=1.09,95 \% \mathrm{CI}\right.$ : $\left.0.98-1.21\right)$ but did not reach formal statistical significance (Figure 2). Mutual adjustment for adiposity measures attenuated risk estimates for all measures of body fat distribution, i.e. WC, WHR, and HC. In contrast, the HR for BMI increased to 1.15 per 1-s.d. increment and remained statistically significant (95\% CI: $1.09-1.22$; Model 3Supplementary Figure S1).
For CRC, findings were more consistent across the four adiposity measures with little evidence for heterogeneity across studies (all $I^{2}<36 \%$, all $P_{\text {heterogeneity }}>0.17$ ), although the risk estimates for EPIC Spain followed a similar pattern as for 'obesityrelated cancers' (Figure 3) including reduced heterogeneity after omitting EPIC Spain (data not shown). Effect sizes for CRC were in general higher with strongest associations observed for WC $\left(\mathrm{HR}_{1 \text {-s.d. increase }}=1.21,95 \% \mathrm{CI}: 1.08-1.35\right)$ and the weakest for $\mathrm{HC}$ $\left(\mathrm{HR}_{1 \text {-s.d. } \text { increase }}=1.15,95 \% \mathrm{CI}: 1.01-1.32\right)$. After mutual adjustment for adiposity measures, only BMI remained a significant risk factor of CRC $\left(\mathrm{HR}_{1-\text { s.d. }} \quad\right.$ increase $=1.19,95 \%$ CI: $1.08-1.31$; Supplementary Figure S1).

For postmenopausal breast cancer, a significant positive association was observed with BMI but only after additional adjustment for HC and WC (model 3) with a HR per 1-s.d. increase in BMI of 1.15 (95\% CI: 1.03-1.27; Supplementary Figure S1). Associations with other measures of adiposity were nonsignificant although effect sizes were comparable, except for WHR (Figure 4). In addition, heterogeneity across studies was high for

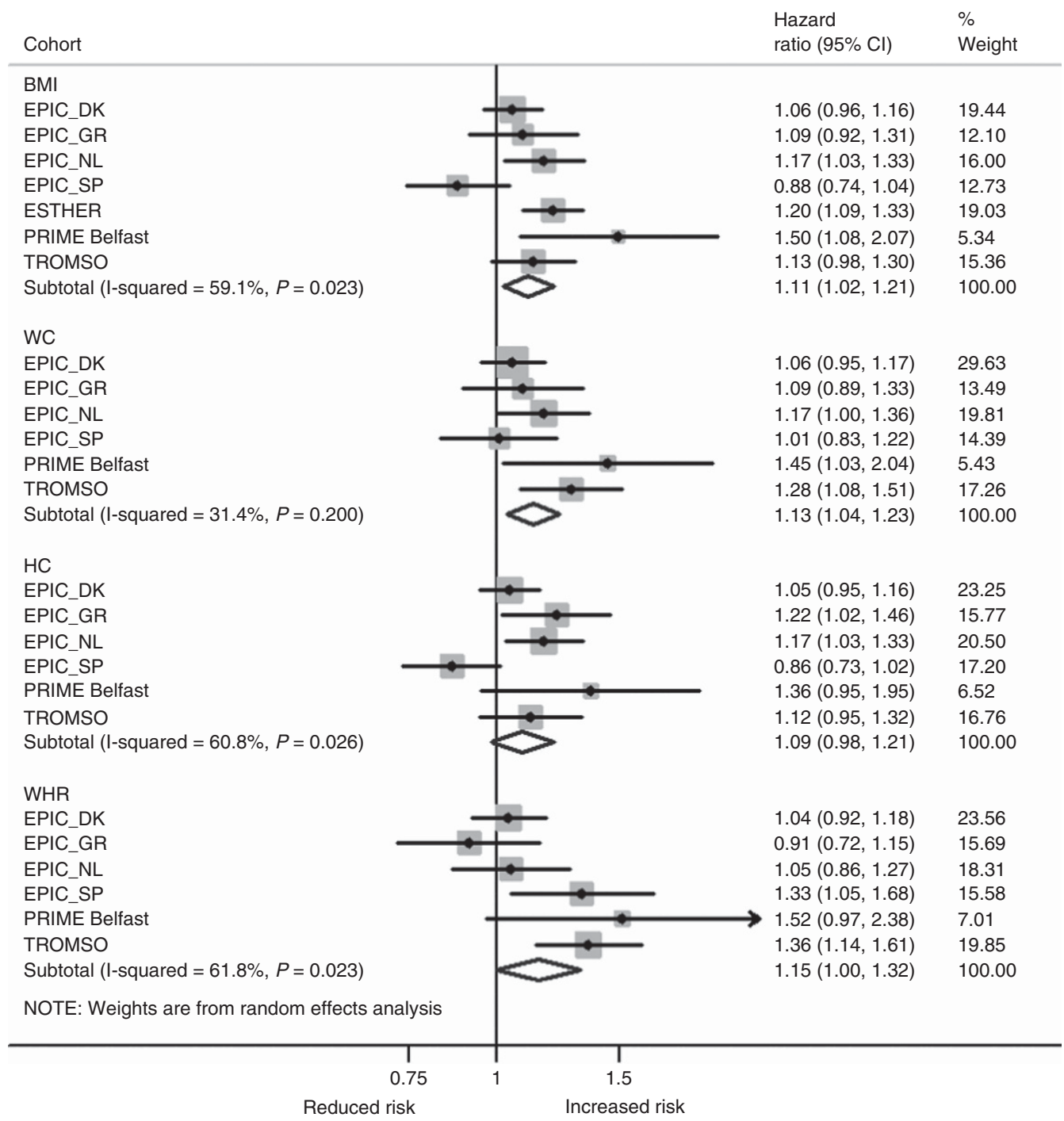

Figure 2. Random-effects meta-analysis of the association of different obesity indicators per 1 standard deviation (s.d.) increment with 'obesityrelated cancers' ${ }^{\prime a}$ ' ${ }^{2}$ irst primary cancers of the breast (postmenopausal), colorectum, lower oesophagus, cardia stomach, liver, gallbladder, pancreas, endometrium, ovary, and kidney. Adjustments were made for sex, age at entry, daily smoking (never, former, current, missing), average alcohol consumption (g per day), education (primary or less, more than primary but less than college, college or university, missing), vigorous physical activity (yes, no, missing), recruitment year, and height. BMI=body mass index; DK=Denmark; $\mathrm{GR}=\mathrm{Greece} ; \mathrm{HC}=$ hip circumference; $\mathrm{NL}=$ The Netherlands; $\mathrm{SP}=$ Spain; $\mathrm{WC}=$ waist circumference; $\mathrm{WHR}=$ waist-to-hip ratio. 


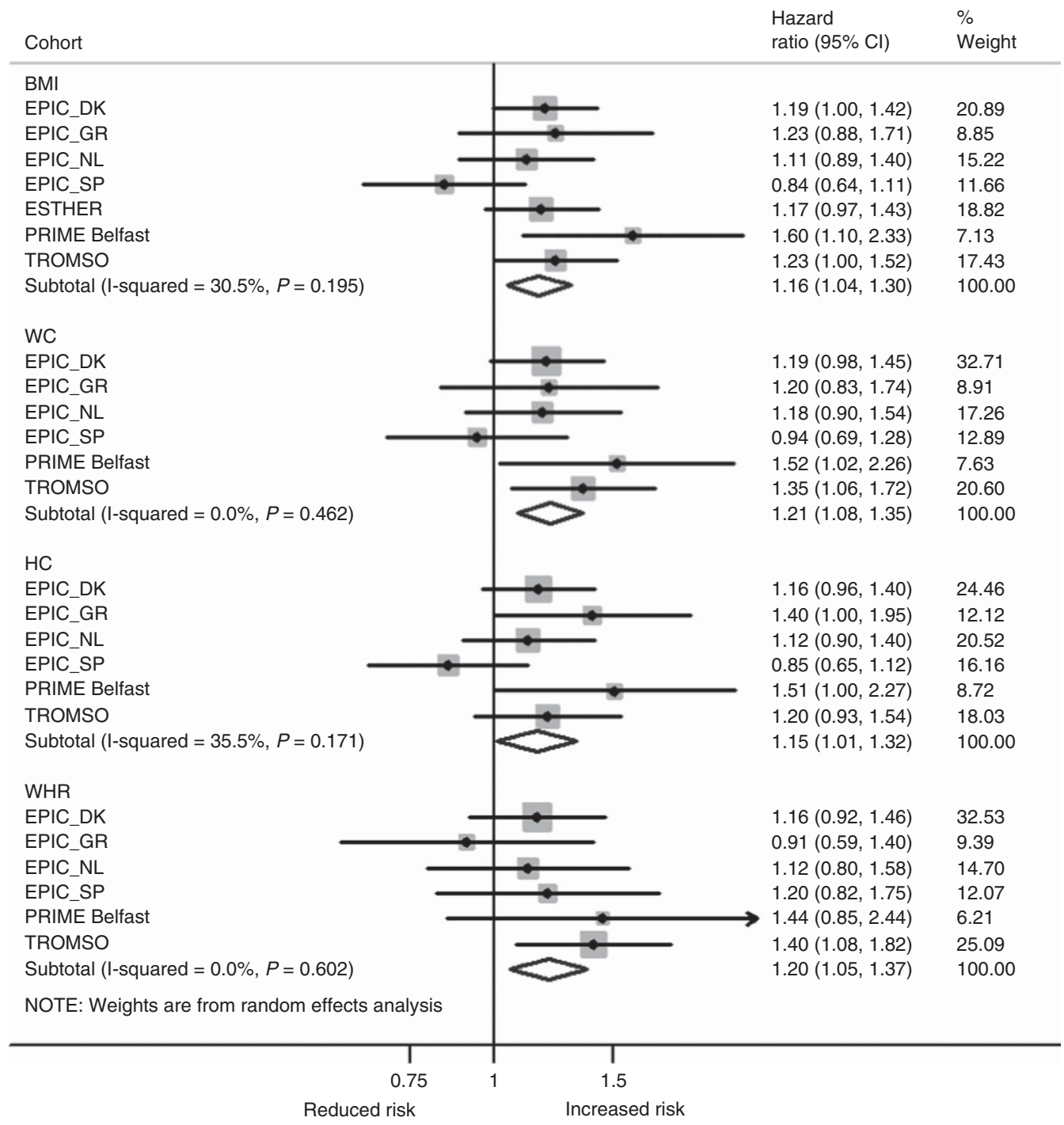

Figure 3. Random-effects meta-analysis of the association of different obesity indicators per 1 standard deviation (s.d.) increment with colorectal cancer. Adjustments were made for sex, age at entry, daily smoking (never, former, current, missing), average alcohol consumption (g per day), education (primary or less, more than primary but less than college, college or university, missing), vigorous physical activity (yes, no, missing), recruitment year, and height. $\mathrm{BMI}=$ body mass index; $\mathrm{DK}=$ Denmark; $\mathrm{GR}=$ Greece; $\mathrm{HC}=$ hip circumference; $\mathrm{NL}=\mathrm{The} \mathrm{Netherlands;} \mathrm{SP}=\mathrm{Spain}$; $\mathrm{WC}=$ waist circumference; $\mathrm{WHR}=$ waist-to-hip ratio.

relative risks associated with WHR $\left(I^{2}=66 \%, P_{\text {heterogeneity }}=0.02\right)$ and did not change after excluding EPIC Spain.

WHR was strongest and most consistently associated with 'other obesity-related cancers' (i.e. lower oesophagus, gastric cardia, liver, gallbladder, pancreas, endometrium, ovary, and kidney) with a HR per 1-s.d. increase of 1.20 (95\% CI: 1.04-1.38; Figure 5). All other obesity measures were non-significant. After mutual adjustment for adiposity measures, WC was also independently associated with 'other obesity-related cancers' $\left(\mathrm{HR}_{1-\text {-s.d. increase }}=1.15,95 \% \mathrm{CI}\right.$ : 1.03-1.28; Supplementary Figure S1), while the association with WHR was marginally attenuated.

All estimates for the association between the four adiposity measures by cancer site and cohort, and the pooled estimates for the different models are presented in Supplementary Table S2.

Dose-response associations. After pooling all cohorts into one dataset, clear linear dose-response associations were found between all adiposity measures and 'obesity-related cancers', except for WHR $\left(P_{\text {non-linear }}=0.02\right)$, where an increased cancer risk became apparent only at values $>0.96$ of the WHR (Supplementary Figure S2). For CRC, linear dose-response associations were observed for all four adiposity measures (Supplementary Figure S2). For postmenopausal breast and 'other obesity-related cancers', dose-response relationships were inconsistent across the four obesity measures and linearity largely statistically insignificant (Supplementary Figure S3). These findings were confirmed when analysing BMI and WC in pre-defined categories (Supplementary Table S6).

Direct comparisons between anthropometric indicators. Cindices for WC, HC, and WHR were marginally and nonsignificantly lower than for BMI in predicting risk of 'obesityrelated cancers', CRC, postmenopausal breast cancer (range of C-index differences to BMI: -0.01 to -0.02 ) and vice versa for 'other obesity-related cancers'(range of C-index differences to BMI: 0.02 to 0.03 ; Table 2). Compared to a null model including all confounding variables but none of the four anthropometric indicators, adding BMI, WC, HC, and WHR separately or jointly resulted in virtually similar model fit as evaluated by AIC (Table 2).

Effect modification by sex, smoking, HT use, and weight status. After stratification by sex, the risks for 'obesity-related cancers' associated with BMI and WC were comparable between 


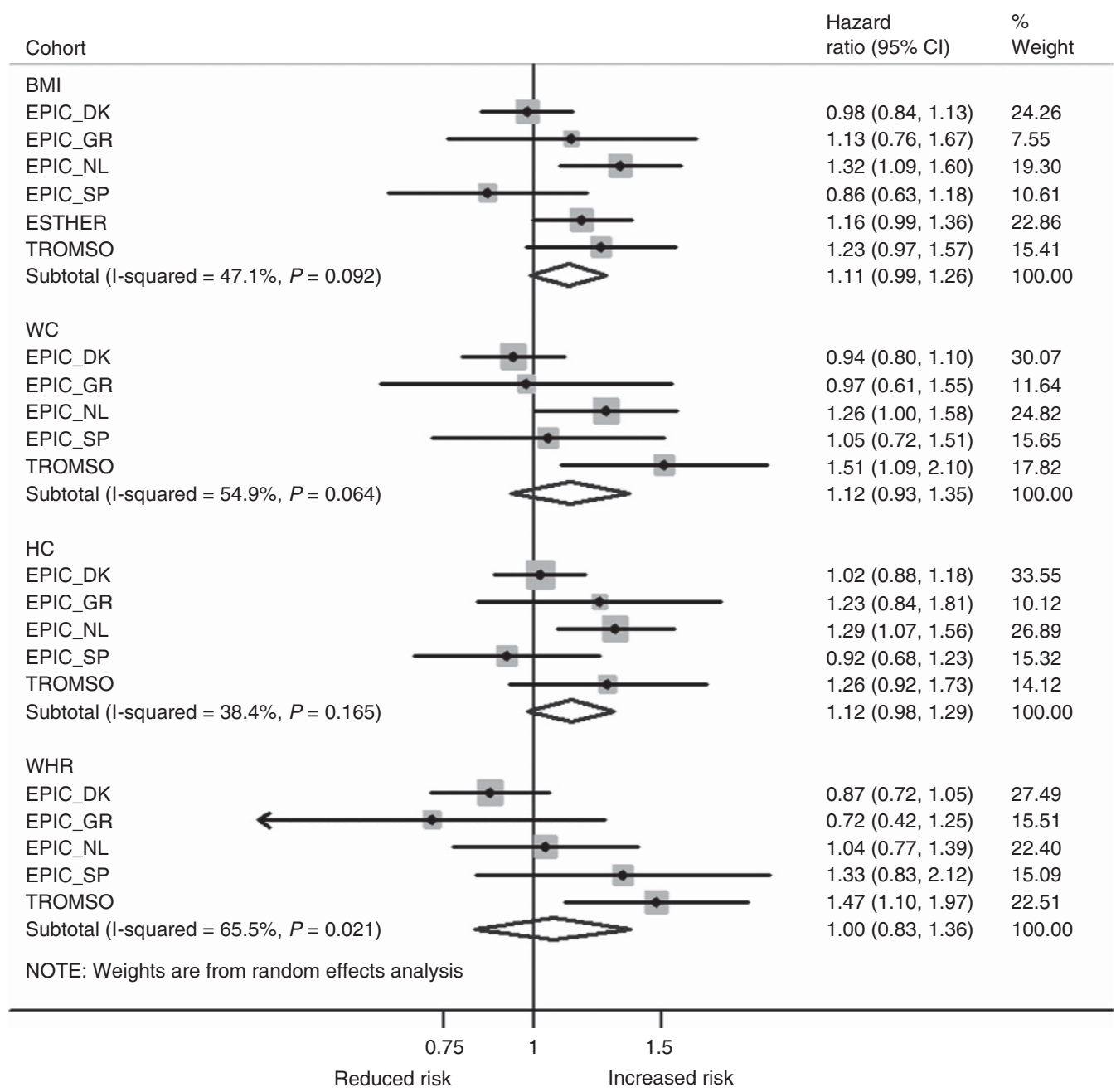

Figure 4. Random-effects meta-analysis of the association of different obesity indicators per 1 standard deviation (s.d.) increment with postmenopausal breast cancer. Adjustments were made for age at entry, daily smoking (never, former, current, missing), average alcohol consumption (g per day), education (primary or less, more than primary but less than college, college or university, missing), vigorous physical activity (yes, no, missing), recruitment year, and height. $\mathrm{BMI}=$ body mass index; $\mathrm{DK}=$ Denmark; $\mathrm{GR}=\mathrm{Greece}$; $\mathrm{HC}=$ hip circumference; $\mathrm{NL}=$ The Netherlands; $\mathrm{SP}=$ Spain; $\mathrm{WC}=$ waist circumference; $\mathrm{WHR}=$ waist-to-hip ratio.

men and women (Supplementary Table S3). However, HC yielded higher risk estimates in women for 'obesity-related cancers' and CRC. On the other hand, WHR yielded higher risk estimates in men compared to women for 'obesity-related cancers', CRC, and 'other obesity-related cancers'. Some of these sex-specific differences became more pronounced or only apparent after mutual adjustment for adiposity measures (Model 3; Supplementary Table S3).

Some variability in risk estimates was observed across smoking categories (Supplementary Table S4). However, formal tests for effect modification were only significant for associations between $\mathrm{HC}$ and CRC $\left(P_{\text {interaction }}=0.02\right)$ with a significantly increased risk observed in never smokers $\left(\mathrm{HR}_{1-\text { s.d. }}\right.$ increase $=1.33,95 \% \mathrm{CI}$ : $1.16-1.54)$.

For postmenopausal breast cancer, significantly increased risks were observed in women who never used HT, with similar effect sizes of $\sim 20 \%$ increased risk per 1-s.d. increase of BMI, WC, and HC $\left(P_{\text {interaction }}<0.001\right)$ (Model 2, Supplementary Table S5).

No significant interactions between measures of body fat distribution (i.e., WC, HC, and WHR) and World Health Organizations' BMI categories (normal weight: $\mathrm{BMI}<25 \mathrm{~kg} \mathrm{~m}^{-2}$, overweight: $\mathrm{BMI} \geqslant 25$ to $<30 \mathrm{~kg} \mathrm{~m}^{-2}$, obesity: $\mathrm{BMI} \geqslant 30 \mathrm{~kg} \mathrm{~m}^{-2}$ ) in relation to 'obesity-related cancers' and CRC or postmenopausal breast cancer were observed (data not shown). A borderline significant interaction for associations between $\mathrm{WC}$ and $\mathrm{CRC}$ across categories of BMI was observed $\left(P_{\text {interaction }}=0.07\right)$ showing a significantly increased risk of $\mathrm{CRC}\left(\mathrm{HR}_{1-\text { s.d. increase }}=1.52,95 \%\right.$ CI: 1.20-1.92) in the overweight category.

\section{DISCUSSION}

In this pooled analysis of seven prospective cohort studies, we observed increased risks of 'obesity-related cancers', overall and of $\mathrm{CRC}$ and postmenopausal breast cancer associated with equivalent increments of general adiposity (BMI) and measures of body fat distribution (WC, HC, and WHR). Relative risk estimates were comparable across the different adiposity indices. For postmenopausal breast cancer, there was indication that increased risks were confined to women who never used HT. When mutually adjusting for all four anthropometric measures, which may be linked to different underlying biological mechanisms, BMI appeared to be an independent risk factor of 'obesity-related cancers', CRC, and postmenopausal breast cancer. In contrast, WC and WHR appeared to be independent risk factors of 'other obesity-related cancers', which we could not analyse separately due to low number of cases. To our knowledge, this is the first study of older adults to 


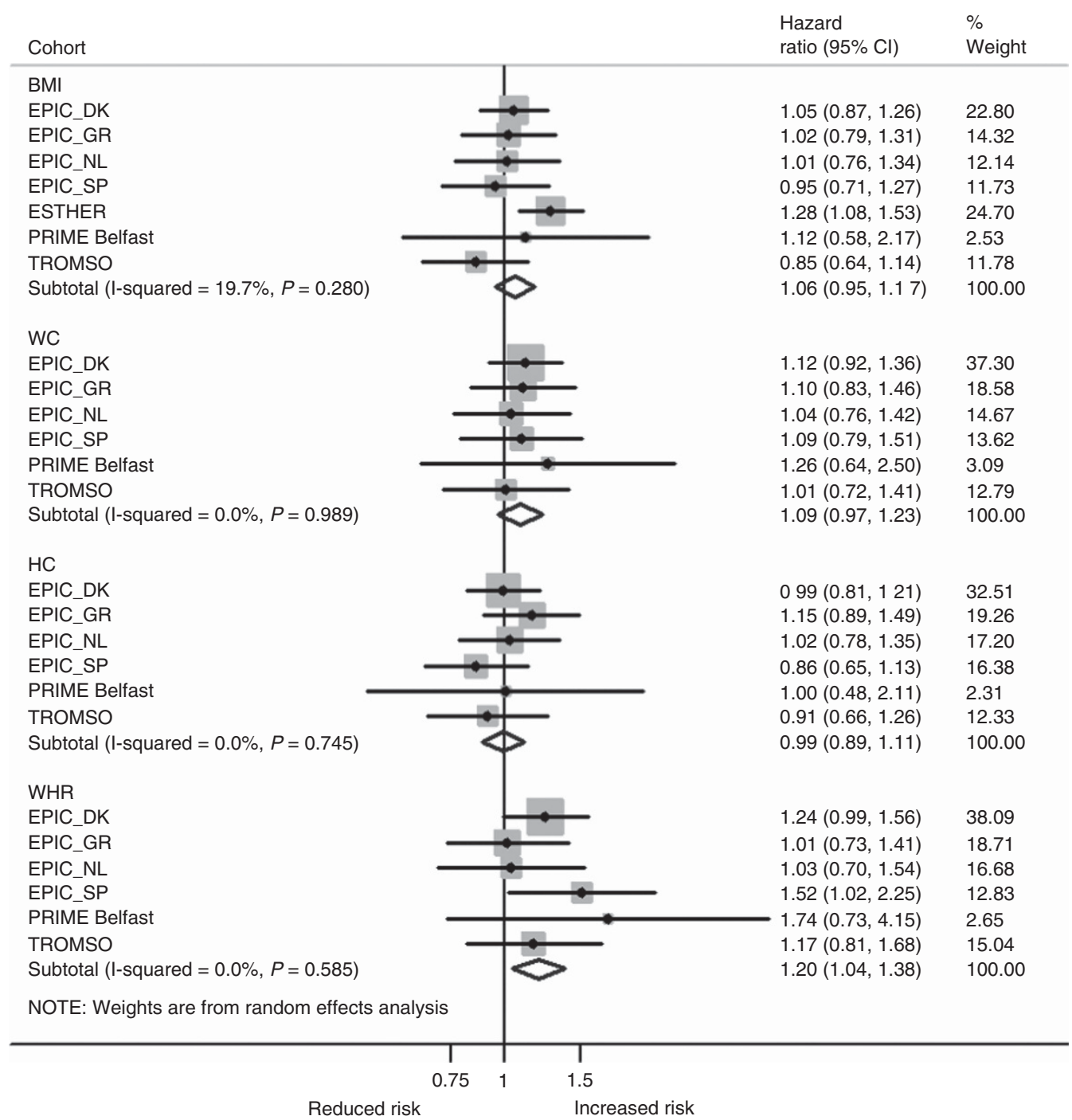

Figure 5. Random-effects meta-analysis of the association of different obesity indicators per 1 standard deviation (s.d.) increment with 'other obesity-related cancers'a ${ }^{\prime a}$ 'First primary cancers of the lower oesophagus, cardia stomach, liver, gallbladder, pancreas, endometrium, ovary, and kidney. Adjustments were made for sex, age at entry, daily smoking (never, former, current, missing), average alcohol consumption (g per day), education (primary or less, more than primary but less than college, college or university, missing), vigorous physical activity (yes, no, missing), recruitment year, and height. $\mathrm{BMI}=$ body mass index; $\mathrm{DK}=$ Denmark; $\mathrm{GR}=\mathrm{Greece} ; \mathrm{HC}=$ hip circumference; $\mathrm{NL}=$ the Netherlands; $\mathrm{SP}=\mathrm{Spain}$; WC $=$ waist circumference; $W H R=$ waist-to-hip ratio.

comprehensively compare anthropometric measures of general adiposity and body fat distribution, to examine and quantify the respective independent effects of these measures and to examine the shape of the dose-response relationship for cancers known to be obesity-related.

Our analysis does not corroborate the hypothesis that central adiposity is a superior predictor of CRC or postmenopausal breast cancer among older adults, as proposed by some previous studies (Pischon et al, 2006; Stolzenberg-Solomon et al, 2013; White et al, 2015). In contrast, and in line with our results, is an analysis of the NIH-AARP Diet and Health Study, where BMI, WC, and WHR were found to be equally discriminatory for colon cancer risk (Keimling et al, 2013). HC was not associated with risk of colon cancer in Keimling et al, while in our analysis HC virtually mirrored results for BMI, albeit effect sizes were slightly lower as compared to BMI. HC in disease models that do not account for $\mathrm{BMI}$ and/or WC is probably more indicative of general adiposity rather than an indicator of fat accumulation in the lower extremities reflected by a high correlation between $\mathrm{HC}$ and BMI (Pearson correlation $\sim 0.8$ in our data). Mutual adjustment of obesity indicators may reduce heterogeneity across studies as observed in our data. This could indicate that BMI does not capture general adiposity equally well in all White Caucasians and that holding WC and $\mathrm{HC}$ constant, improves the interpretation of BMI as a measure of general adiposity.

Furthermore, in the Cancer Prevention Study-II Nutrition Cohort, positive associations between $\mathrm{WC}$ and BMI and postmenopausal breast cancer risk were reported, but only the association with BMI remained significant after mutual adjustment (Gaudet et al, 2014).

For postmenopausal breast cancer, early results from the Iowa Women Health Study suggested a statistically significant multiplicative interaction between BMI and WHR (Folsom et al, 2000). However, in subsequent reports that specifically tested interactions between BMI and indicators of central adiposity in relation to risk of CRC (Keimling et al, 2013) and breast cancer (Gaudet et al, 2015), no statistically significant associations were found. Our findings are in line with these more recent reports in that we did not find statistically significant multiplicative interactions between BMI and any of the three measures of body fat distribution. 
Table 2. Changes in risk discrimination for the risk of incident cancer in men and women combined after addition of anthropometric indicators to the null model

\begin{tabular}{|c|c|c|c|c|c|c|c|c|c|c|c|c|}
\hline & \multicolumn{2}{|c|}{ Null model } & \multicolumn{2}{|c|}{ BMI } & \multicolumn{2}{|c|}{ WC } & \multicolumn{2}{|c|}{$\mathrm{HC}$} & \multicolumn{2}{|c|}{ WHR } & \multicolumn{2}{|c|}{$\mathrm{BMI}+\mathrm{WC}+\mathrm{HC}$} \\
\hline & Estimate & $95 \% \mathrm{Cl}$ & Estimate & $95 \% \mathrm{Cl}$ & Estimate & $95 \% \mathrm{Cl}$ & Estimate & $95 \% \mathrm{Cl}$ & Estimate & $95 \% \mathrm{Cl}$ & Estimate & $95 \% \mathrm{Cl}$ \\
\hline \multicolumn{13}{|c|}{ Obesity-related cancers $^{a}$} \\
\hline $\mathrm{AIC}$ & 15826.6 & & 15823.6 & & 15820.6 & & 15823.7 & & 15823.4 & & 15823.1 & \\
\hline C-index & 0.688 & $0.676-0.699$ & 0.687 & $0.675-0.698$ & 0.663 & $0.649-0.677$ & 0.663 & $0.650-0.677$ & 0.664 & $0.651-0.678$ & 0.663 & $0.650-0.677$ \\
\hline \multicolumn{13}{|c|}{ Colorectal cancer } \\
\hline $\mathrm{AIC}$ & 5678.8 & & 5672.8 & & 5670.2 & & 5674.8 & & 5674.0 & & 5673.5 & \\
\hline C-index & 0.688 & $0.667-0.709$ & 0.689 & $0.668-0.711$ & 0.680 & $0.655-0.704$ & 0.679 & $0.655-0.704$ & 0.681 & $0.657-0.706$ & 0.681 & $0.656-0.705$ \\
\hline \multicolumn{13}{|c|}{ Breast cancer $^{\text {b }}$} \\
\hline $\mathrm{AlC}$ & 5031.2 & & 5030.3 & & 5031.9 & & 5032.0 & & 5033.1 & & 5032.9 & \\
\hline C-index & 0.824 & $0.813-0.836$ & 0.823 & $0.812-0.835$ & 0.801 & $0.787-0.815$ & 0.802 & $0.788-0.816$ & 0.803 & $0.789-0.817$ & 0.801 & $0.787-0.815$ \\
\hline \multicolumn{13}{|c|}{ Other obesity-related cancers ${ }^{c}$} \\
\hline $\mathrm{AIC}$ & 4780.7 & & 4782.7 & & 4781.4 & & 4782.2 & & 4777.0 & & 4780.6 & \\
\hline C-index & 0.588 & $0.561-0.615$ & 0.587 & $0.559-0.614$ & 0.605 & $0.573-0.637$ & 0.605 & $0.574-0.637$ & 0.612 & $0.581-0.643$ & 0.618 & $0.587-0.648$ \\
\hline \multicolumn{13}{|c|}{$\begin{array}{l}\text { Abbreviations: } \mathrm{AIC}=\text { Akaike Information Criterion; } \mathrm{BMI}=\text { body mass index; } \mathrm{Cl}=\text { confidence interval; } \mathrm{HC}=\text { hip circumference; WC=waist circumference; WHR= waist-to-hip ratio. Note: Null } \\
\text { model included sex, age, daily smoking (never, former, current, and missing), average alcohol consumption (g/d), education (primary or less, more than primary but less than college, college or } \\
\text { university, missing), vigorous physical activity (yes, no, and missing), recruitment year, and height. } \\
{ }^{2} \text { First primary cancers of the breast (postmenopausal), colorectum, lower oesophagus, cardia stomach, liver, gallbladder, pancreas, endometrium, ovary, and kidney. } \\
\text { b }_{\text {Women only. }} \\
{ }^{c} \text { Same as all obesity-related cancers but excluding first primary cancers of the breast and of the colorectum. }\end{array}$} \\
\hline
\end{tabular}

For most of the cancer sites that we grouped into 'other obesityrelated cancers' due to the small number of cases, previous studies reported somewhat stronger associations with regard to measures of central adiposity as compared to BMI, which is in line with our findings. For example, in the meta-analysis of Aune et al on pancreatic cancer, WHR yielded an overall RR of 1.19 (95\% CI: 1.09-1.31), while that for BMI was 1.10 (95\% CI: 1.07-1.14; Aune et al, 2012). Slightly stronger associations for WC and WHR, as compared to BMI, were also reported in the most recent WCRF/ AICR pooled analyses for advanced prostate cancer (World Cancer Research Fund/American Institute for Cancer Research, 2014). We were not able to include prostate cancer in our analysis because of lack of data by stage.

In an analysis using data from the large EPIC prospective cohort, we reported previously that abdominal obesity, rather than general obesity, is a risk factor for the development of oesophageal adenocarcinoma and gastric cardia cancer (Steffen et al, 2015). In the prospective NIH-AARP cohort both overall adiposity (BMI) and abdominal adiposity (WC, WHR) were associated with a higher risk of oesophageal adenocarcinoma, but only BMI was associated with a higher risk of gastric cardia adenocarcinoma (O'Doherty et al, 2012). In an updated WCRF/AICR meta-analysis, BMI was more strongly associated with an increased risk of endometrial cancer compared to WC or WHR, although WC was also associated with an increased risk (Aune et al, 2015b). Similarly, an increased risk of ovarian cancer was reported with greater BMI and a marginally significant positive association with WC, but no association was found for HC or WHR (Aune et al, 2015a). We are not aware of studies investigating the role of body fat distribution and risk of cancers of the liver and gallbladder. The evidence with regard to BMI was judged convincing for both of these cancer sites by the most recent WCRF/AICR pooled analyses (World Cancer Research Fund/American Institute for Cancer Research., 2015a, b). For these last two cancer sites, further assessment of the impact of body fat distribution in future studies is warranted.

Although WC and WHR (and HC as noted above) have been interpreted as measures of body fat distribution, they may well also be markers of general adiposity (Anderson et al, 2015). In the current study, we saw that these measures have associations with cancer that are similar to those for BMI, but mostly when used in separate models. However, few studies have conducted mutual adjustments between BMI and measures of body fat distribution to try to clarify their independent roles. This is a limitation, which needs further assessment in future studies because it may provide insight into the biologic mechanisms underlying observed associations between adiposity and cancer risk (Keimling et al, 2013). Ideally, for mutual adjustment of BMI and measures of body fat distribution, residuals of measures of WC and/or HC should be used in order to retain the interpretability of BMI as an indicator of general adiposity and to avoid potential problems of multicollinearity. Otherwise, BMI is not easily interpretable or becomes an indicator of muscularity rather than adiposity $(\mathrm{Hu}, 2008)$. It is also of note that WC, HC, and WHR have larger measurement errors compared with measurement of BMI, which may affect the reliability of respective risk estimates and calls for additional caution when comparing results between these indicators.

Links between greater adiposity and increased risk of many cancers are biologically plausible considering that obesity is related to a vast array of metabolic and physiological dysfunctions (Park et al, 2014). A number of these altered processes have specifically been implicated in cancer development; notably (1) abnormalities of insulin resistance and the IGF-I system; described as the insulinIGF-I-insulin pathway, which may promote tumour development at many anatomic sites (Park et al, 2014; Renehan et al, 2015); (2) the impact of adiposity on the biosynthesis and bioavailability of endogenous sex steroids (e.g., oestradiol) which applies predominantly, but not exclusively, to postmenopausal breast, endometrial and ovarian cancers (Park et al, 2014; Renehan et al, 2015); our findings that obesity-associated risk of postmenopausal breast cancer was strongest in women, who never used HT support that hypothesis; (3) obesity induced low-grade chronic systemic inflammation; and (4) alterations in the levels of adipocyte-derived factors, known as adipokines (Lee et al, 2015). All of these proposed pathways have been extensively investigated in mechanistic studies and tested in epidemiological settings. For example, adiponectin, one of the most abundant adipokines, has been shown to be a key mediator in the development of several types of obesityrelated cancers including endometrial, breast, advanced prostate, CRC, renal, and pancreatic (Dalamaga et al, 2012). Unlike most of the other adipose tissue derived adipokines, serum adiponectin is reduced in obesity and correlates inversely with BMI, WC, HC, and 
WHR, independently of age and menopausal status (Dalamaga et al, 2012). Migrating adipose progenitor cells, which can be found in high concentration in white adipose tissue and may acquire a tumour-promoting function, and the gut microbiome are two emerging mechanistic hypotheses linking obesity with cancer risk (Renehan et al, 2015).

Our study has some limitations that may affect the interpretation of the results. Despite the pooling of seven cohorts, we were not able to compare adiposity measures across all anatomical cancer sites with strong evidence of an association with obesity because of low numbers of cases. These cancer sites were therefore combined in 'other obesity-related cancers'. For this reason, we could not investigate whether one or several of these cancers may have driven the observed associations with WC and WHR. Also related to the low number of cases, we were not able to sub-divide $\mathrm{CRC}$ in its anatomical sub-sites - knowing that effects sizes are more pronounced for cancers of the colon as compared to the rectum (World Cancer Research Fund/American Institute for Cancer Research, 2011) - or to sub-divide breast cancer by receptor status. However, associations with BMI appear to be unrelated to receptor status in postmenopausal women who have never used HT (Renehan et al, 2015).

Further limitations of our study are related to differences in study design between cohorts, including differences in length of follow-up and assessment of several covariates. In order to harmonise the data and variable definitions across cohorts, some covariates such as physical activity were only available in binary form (yes/no). Despite adjustment for the main confounding factors, namely smoking and physical activity, we cannot rule out confounding by other unmeasured factors, most importantly reproductive factors and diet. As these were not consistently available from all cohorts, we were not able to take these into account in our analyses. However, we do not expect risk estimates being noticeably confounded by diet as has been shown previously (Renehan et al, 2012). In the ESTHER study, BMI based on selfreported height and weight was the only adiposity indicator available. Although self-reported BMI may grossly underestimate prevalence of adiposity at the population level, ranking of individuals according to their BMI is less affected $(\mathrm{Hu}, 2008)$. Furthermore, study-specific risk estimates for ESTHER were consistent with the other cohorts and the summary estimates; excluding ESTHER from the meta-analysis had virtually no effect on the summary estimates (data not shown). Keeping ESTHER in our analysis also facilitates comparison of results with our companion paper, where we investigated the impact of overweight duration on obesity-related cancers (Arnold et al, 2016a). Finally, we did not a priori stratify our analysis by sex, mainly due to sample size considerations. However, in secondary analysis, largely similarly increased risks among men and women were observed for the investigated adiposity indicators (Supplementary Table S3).

Strengths of our study include the availability of harmonised individual-level data for the estimation of cohort-specific risk estimates. This allowed us to use the same exposure definitions, disease end points, and multivariate models in all included studies. Our investigation included only prospective cohort studies, which reduces the potential of biases that are often reason for concern in retrospective studies, for example, recall and selection bias. Individuals within each of our cohorts were largely White Caucasian, which adds further validity to our results because the effects of a given WC in a White population may be very different to the same WC in an Asian or African-American population. However, these potential ethic differences need to be evaluated in future studies. Further, we explored and compared, to our knowledge, for the first time in a pooled analysis of cohorts consisting of middle-aged and older adults, non-linear associations between BMI, WC, HC, and WHR for cancer sites known to be adiposity-related.

\section{CONCLUSIONS}

General adiposity as measured by BMI and body fat distribution as measured by WC, HC, or WHR show comparable positive associations with obesity-related cancers combined, with CRC, and with postmenopausal breast cancer. For postmenopausal breast cancer there was evidence for effect modification by HT use, which needs further exploration in other cohorts and populations. Avoiding abdominal fatness may also be important for specific cancer sites, but requires further investigation. Overall, our results underscore the importance of avoiding excess body fatness for cancer prevention irrespective of age and gender.

\section{ACKNOWLEDGEMENTS}

Data used throughout the present study are derived from the CHANCES project. The project is coordinated by the Hellenic Health Foundation, Greece. The project received funding by the FP7 framework programme of DG-RESEARCH in the European Commission (grant agreement no. HEALTH-F3-2010-242244). EPIC Greece: funded by the Hellenic Health Foundation. EPIC Netherlands: funded by European Commission (DG SANCO); Dutch Ministry of Public Health, Welfare and Sports (VWS); The National Institute for Public Health and the Environment; the Dutch Cancer Society, the Netherlands Organisation for Health Research and Development (ZONMW); World Cancer Research Fund (WCRF). EPIC Spain: supported by Health Research Fund (FIS) of the Spanish Ministry of Health RTICC 'Red Temática de Investigación Cooperativa en Cáncer (grant numbers: Rd06/0020/ 0091 and Rd12/0036/0018), Regional Governments of Andalucía, Asturias, Basque Country, Murcia (project 6236), and Navarra, Instituto de Salud Carlos III, Redes de Investigacion Cooperativa (RD06/0020). ESTHER: funded by the Baden-Württemberg state Ministry of Science, Research and Arts (Stuttgart, Germany), the Federal Ministry of Education and Research (Berlin, Germany), and the Federal Ministry of Family Affairs, Senior Citizens, Women and Youth (Berlin, Germany). PRIME Belfast: supported by grants from the Institut National de la Santé et de la Recherche Médicale (INSERM), the Merck, Sharp \& Dohme-Chibret Laboratory and the Northern Ireland Health \& Social Care Research and Development Office. Tromsø: funded by: UiT The Arctic University of Norway, the National Screening Service, and the Research Council of Norway.

\section{CONFLICT OF INTEREST}

The authors declare no conflict of interest.

COLLABORATORS ON BEHALF OF THE CHANCES CONSORTIUM

Kari Kuulasmaa, Ben Schöttker, Ute Mons, Kai-Uwe Saum, Bernd Holleczek, Alun Evans, John Yarnell.

\section{REFERENCES}

Anderson AS, Key TJ, Norat T, Scoccianti C, Cecchini M, Berrino F, Boutron-Ruault MC, Espina C, Leitzmann M, Powers H, Wiseman M, Romieu I (2015) European code against cancer 4th edition: Obesity, body fatness and cancer. Cancer Epidemiol 39(Suppl 1): S34-S45.

Arnold M, Freisling H, Stolzenberg-Solomon R, Kee F, O'Doherty MG, Ordóñez-Mena JM, Wilsgaard T, May AM, Bueno-de-Mesquita HB, 
Tjønneland A, Orfanos P, Trichopoulou A, Boffetta P, Bray F, Jenab M, Soerjomataram I, CHANCES consortium (2016a) Overweight duration in older adults and cancer risk: a study of cohorts in Europe and the United States. Eur J Epidemiol 31: 893-904.

Arnold M, Leitzmann M, Freisling H, Bray F, Romieu I, Renehan A, Soerjomataram I (2016b) Obesity and cancer: An update of the global impact. Cancer Epidemiol 41: 8-15.

Aune D, Greenwood DC, Chan DSM, Vieira R, Vieira AR, Navarro Rosenblatt DA, Cade JE, Burley VJ, Norat T (2012) Body mass index, abdominal fatness and pancreatic cancer risk: A systematic review and non-linear dose-response meta-analysis of prospective studies. Ann Oncol 23: 843-852.

Aune D, Navarro Rosenblatt Da, Chan DSM, Abar L, Vingeliene S, Vieira AR, Greenwood DC, Norat T (2015a) Anthropometric factors and ovarian cancer risk: A systematic review and nonlinear dose-response metaanalysis of prospective studies. Int J Cancer 136: 1888-1898.

Aune D, Navarro Rosenblatt DA, Chan DSM, Vingeliene S, Abar L, Vieira AR, Greenwood DC, Bandera EV, Norat T (2015b) Anthropometric factors and endometrial cancer risk: a systematic review and dose-response metaanalysis of prospective studies. Ann Oncol 26: 1635-1648.

Bhaskaran K, Douglas I, Forbes H, Dos-Santos-Silva I, Leon DA, Smeeth L (2014) Body-mass index and risk of 22 specific cancers: a populationbased cohort study of 5 24 million UK adults. Lancet 384: 755-765.

Boffetta P, Bobak M, Borsch-Supan A, Brenner H, Eriksson S, Grodstein F, Jansen E, Jenab M, Juerges H, Kampman E, Kee F, Kuulasmaa K, Park Y, Tjonneland A, van Duijn C, Wilsgaard T, Wolk A, Trichopoulos D, Bamia C, Trichopoulou A (2014) The Consortium on Health and Ageing: Network of Cohorts in Europe and the United States (CHANCES) project-design, population and data harmonization of a large-scale, international study. Eur J Epidemiol 29: 929-936.

Cameron AJ, Magliano DJ, Söderberg S (2013) A systematic review of the impact of including both waist and hip circumference in risk models for cardiovascular diseases, diabetes and mortality. Obes Rev 14: 86-94.

Fibrinogen Studies Collaboration (2009) Measures to assess the prognostic ability of the stratified Cox proportional hazardsmodel. Stat Med 28: 389-411.

Dalamaga M, Diakopoulos KN, Mantzoros CS (2012) The Role of Adiponectin in Cancer: A Review of Current Evidence. Endocr Rev 33: 547-594.

Folsom AR, Kushi LH, Anderson KE, Mink PJ, Olson JE, Hong C-P, Sellers TA, Lazovich D, Prineas RJ (2000) Associations of General and Abdominal Obesity With Multiple Health Outcomes in Older Women. Arch Intern Med 160: 2117-2128.

Gaudet MM, Carter BD, Patel AV, Teras LR, Jacobs EJ, Gapstur SM (2014) Waist circumference, body mass index, and postmenopausal breast cancer incidence in the Cancer Prevention Study-II Nutrition Cohort. Cancer Causes Control 25: 737-745.

Gaudet MM, Kitahara CM, Newton CC, Bernstein L, Reynolds P, Weiderpass E, Kreimer AR, Yang G, Adami H-O, Alavanja MC, Beane Freeman LE, Boeing H, Buring J, Chaturvedi A, Chen Y, D’Aloisio AA, Freedman M, Gao Y-T, Gaziano JM, Giles GG, Hakansson N, Huang W-Y, Lee I-M, Linet MS, MacInnis RJ, Park Y, Prizment A, Purdue MP, Riboli E, Robien K, Sandler DP, Schairer C, Sesso HD, Ou Shu X, White E, Wolk A, Xiang Y-B, Zelenuich-Jacquotte A, Zheng W, Patel AV, Hartge P, Berrington de Gonzalez A, Gapstur SM (2015) Anthropometry and head and neck cancer:a pooled analysis of cohort data. Int J Epidemiol 44: 673-681.

Harris RJ, Bradburn MJ, Deeks JJ, Altman DG, Harbord RM, Sterne JaC (2008) Metan: Fixed- and random-effects meta-analysis. Stata J 8: 3-28.

Heitmann BL, Lissner L (2011) Hip Hip Hurrah! Hip size inversely related to heart disease and total mortality. Obes Rev 12: 478-481.

Higgins JPT, Thompson SG (2002) Quantifying heterogeneity in a metaanalysis. Stat Med 21: 1539-1558.

Hu FB (2008) Obesity epidemiology. Oxford University Press: Oxford New York.

Keimling M, Renehan AG, Behrens G, Fischer B, Hollenbeck AR, Cross AJ, Leitzmann MF (2013) Comparison of associations of body mass index, abdominal adiposity, and risk of colorectal cancer in a Large Prospective Cohort Study. Cancer Epidemiol Biomarkers Prev 22: 1383-1394.

Lauby-Secretan B, Scoccianti C, Loomis D, Grosse Y, Bianchini F, Straif K (2016) Body fatness and cancer-viewpoint of the IARC Working Group. N Engl J Med 375: 794-798.

Lee CH, Woo YC, Wang Y, Yeung CY, Xu A, Lam KSL (2015) Obesity, adipokines and cancer: An update. Clin Endocrinol (Oxf) 83: 147-156.
Moore LL, Bradlee ML, Singer MR, Splansky GL, Proctor MH, Ellison RC, Kreger BE (2004) BMI and waist circumference as predictors of lifetime colon cancer risk in Framingham Study adults. Int J Obes Relat Metab Disord 28: 559-567.

National Heart, Lung and Blood Institute (1998) Clinical Guidelines on the Identification, Evaluation, and Treatment of Overweight and Obesity in Adults: The Evidence Report. Report No, 98-4083.

NCD Risk Factor Collaboration (2016) Trends in adult body-mass index in 200 countries from 1975 to 2014: a pooled analysis of 1698 population-based measurement studies with $19 \cdot 2$ million participants. Lancet 387: 1377-1396.

Ng M, Fleming T, Robinson M, Thomson B, Graetz N, Margono C, Mullany EC, Biryukov S, Abbafati C, Abera SF, Abraham JP, Abu-Rmeileh NME, Achoki T, AlBuhairan FS, Alemu ZA, Alfonso R, Ali MK, Ali R, Guzman NA, Ammar W, Anwari P, Banerjee A, Barquera S, Basu S, Bennett DA, Bhutta Z, Blore J, Cabral N, Nonato IC, Chang J-C, Chowdhury R, Courville KJ, Criqui MH, Cundiff DK, Dabhadkar KC, Dandona L, Davis A, Dayama A, Dharmaratne SD, Ding EL, Durrani AM, Esteghamati A, Farzadfar F, Fay DFJ, Feigin VL, Flaxman A, Forouzanfar MH, Goto A, Green Ma, Gupta R, Hafezi-Nejad N, Hankey GJ, Harewood HC, Havmoeller R, Hay S, Hernandez L, Husseini A, Idrisov BT, Ikeda N, Islami F, Jahangir E, Jassal SK, Jee SH, Jeffreys M, Jonas JB, Kabagambe EK, Khalifa SEAH, Kengne AP, Khader YS, Khang Y-H, Kim D, Kimokoti RW, Kinge JM, Kokubo Y, Kosen S, Kwan G, Lai T, Leinsalu M, Li Y, Liang X, Liu S, Logroscino G, Lotufo PA, Lu Y, Ma J, Mainoo NK, Mensah GA, Merriman TR, Mokdad AH, Moschandreas J, Naghavi M, Naheed A, Nand D, Narayan KMV, Nelson EL, Neuhouser ML, Nisar MI, Ohkubo T, Oti SO, Pedroza A, Prabhakaran D, Roy N, Sampson U, Seo H, Sepanlou SG, Shibuya K, Shiri R, Shiue I, Singh GM, Singh JA, Skirbekk V, Stapelberg NJC, Sturua L, Sykes BL, Tobias M, Tran BX, Trasande L, Toyoshima H, van de Vijver S, Vasankari TJ, Veerman JL, Velasquez-Melendez G, Vlassov VV, Vollset SE, Vos T, Wang C, Wang X, Weiderpass E, Werdecker A, Wright JL, Yang YC, Yatsuya H, Yoon J, Yoon S-J, Zhao Y, Zhou M, Zhu S, Lopez AD, Murray CJL, Gakidou E (2014) Global, regional, and national prevalence of overweight and obesity in children and adults during 1980-2013: a systematic analysis for the Global Burden of Disease Study 2013. Lancet 384: 766-781.

O'Doherty MG, Freedman ND, Hollenbeck AR, Schatzkin A, Abnet CC (2012) A prospective cohort study of obesity and risk of oesophageal and gastric adenocarcinoma in the NIH-AARP Diet and Health Study. Gut 61: 1261-1268.

Orsini N, Greenland S (2011) A procedure to tabulate and plot results after flexible modeling of a quantitative covariate. Stata J 11: 1-29.

Park J, Morley TS, Kim M, Clegg DJ, Scherer PE (2014) Obesity and cancermechanisms underlying tumour progression and recurrence. Nat Rev Endocrinol 10: 455-465.

Pischon T, Lahmann PH, Boeing H, Friedenreich C, Norat T, Tjønneland A, Halkjaer J, Overvad K, Clavel-Chapelon F, Boutron-Ruault MC, Guernec G, Bergmann MM, Linseisen J, Becker N, Trichopoulou A, Trichopoulos D, Sieri S, Palli D, Tumino R, Vineis P, Panico S, Peeters PHM, Bueno-de-Mesquita HB, Boshuizen HC, Van Guelpen B, Palmqvist R, Berglund G, Gonzalez CA, Dorronsoro M, Barricarte A, Navarro C, Martinez C, Quirós JR, Roddam A, Allen N, Bingham S, Khaw KT, Ferrari P, Kaaks R, Slimani N, Riboli E (2006) Body size and risk of colon and rectal cancer in the European Prospective Investigation into Cancer and Nutrition (EPIC). J Natl Cancer Inst 98: 920-931.

Renehan AG, Flood A, Adams KF, Olden M, Hollenbeck AR, Cross AJ, Leitzmann MF (2012) Body mass index at different adult ages, weight change, and colorectal cancer risk in the National Institutes of HealthAARP cohort. Am J Epidemiol 176: 1130-1140.

Renehan AG, Tyson M, Egger M, Heller RF, Zwahlen M (2008) Body-mass index and incidence of cancer: a systematic review and meta-analysis of prospective observational studies. Lancet 371: 569-578.

Renehan AG, Zwahlen M, Egger M (2015) Adiposity and cancer risk: new mechanistic insights from epidemiology. Nat Rev Cancer 15: 484-498.

Roswall N, Freisling H, Bueno-de-Mesquita HBA, Ros M, Christensen J, Overvad K, Boutron-Ruault M-C, Severi G, Fagherazzi G, Chang-Claude J, Kaaks R, Steffen A, Boeing H, Argüelles M, Agudo A, Sánchez M-J, Chirlaque M-D, Barricarte Gurrea A, Amiano P, Wareham N, Khaw K-T, Bradbury KE, Trichopoulou A, Papatesta H-M, Trichopoulos D, Palli D, Pala V, Tumino R, Sacerdote C, Mattiello A, Peeters PH, Ehrnström R, Brennan P, Ferrari P, Ljungberg B, Norat T, Gunter M, Riboli E, Weiderpass E, Halkjaer J (2014) Anthropometric measures and bladder 
cancer risk: A prospective study in the EPIC cohort. Int J Cancer 135: 2918-2929.

Steffen A, Huerta J-M, Weiderpass E, Bueno-de-Mesquita HB, May AM, Siersema PD, Kaaks R, Neamat-Allah J, Pala V, Panico S, Saieva C, Tumino R, Naccarati A, Dorronsoro M, Sánchez-Cantalejo E, Ardanaz E, Quirós JR, Ohlsson B, Johansson M, Wallner B, Overvad K, Halkjaer J, Tjønneland A, Fagherazzi G, Racine A, Clavel-Chapelon F, Key TJ, Khaw K-T, Wareham N, Lagiou P, Bamia C, Trichopoulou A, Ferrari P, Freisling H, Lu Y, Riboli E, Cross AJ, Gonzalez Ca, Boeing H (2015) General and abdominal obesity and risk of esophageal and gastric adenocarcinoma in the European Prospective Investigation into Cancer and Nutrition. Int J Cancer 137: 646-657.

Stolzenberg-Solomon RZ, Schairer C, Moore S, Hollenbeck A, Silverman DT (2013) Lifetime adiposity and risk of pancreatic cancer in the NIH-AARP Diet and Health Study cohort. Am J Clin Nutr 98: 1057-1065.

White AJ, Nichols HB, Bradshaw PT, Sandler DP (2015) Overall and central adiposity and breast cancer risk in the sister study. Cancer 121: 3700-3708.

World Cancer Research Fund/American Institute for Cancer Research (2007) Food, Nutrition, Physical Activity, and the Prevention of Cancer: a Global Perspective. (AICR: Washington DC, USA).
World Cancer Research Fund/American Institute for Cancer Research (2011) Continuous Update Project Report. Food, Nutrition, Physical Activity, and the Prevention of Colorectal Cancer.

World Cancer Research Fund/American Institute for Cancer Research (2014) Continuous Update Project Report: Diet, Nutrition, Physical Activity, and Prostate Cancer. Available at: www.wcrf.org/sites/default/files/ProstateCancer-2014-Report.pdf.

World Cancer Research Fund/American Institute for Cancer Research (2015a) Continuous Update Project Report: Diet, Nutrition, Physical Activity and Gallbladder Cancer. Available at: http://www.wcrf.org/sites/default/files/ Gallbladder-Cancer-2015-Report.pdf.

World Cancer Research Fund/American Institute for Cancer Research (2015b) Continuous Update Project Report: Diet, Nutrition, Physical Activity and Liver Cancer. Available at: wcrf.org/sites/default/files/LiverCancer-2015-Report.pdf.

This work is published under the standard license to publish agreement. After 12 months the work will become freely available and the license terms will switch to a Creative Commons AttributionNonCommercial-Share Alike 4.0 Unported License.

${ }^{1}$ Section of Nutrition and Metabolism, International Agency for Research on Cancer (IARC-WHO), 150 Cours Albert Thomas, 69008 Lyon, France; ${ }^{2}$ Section of Cancer Surveillance, International Agency for Research on Cancer (IARC-WHO), 150 Cours Albert Thomas, 69008 Lyon, France; ${ }^{3}$ UKCRC Centre of Excellence for Public Health, School of Medicine, Dentistry and Biomedical Sciences, Queen's University Belfast, University Road, Belfast BT7 1NN, UK; ${ }^{4}$ Network Aging Research (NAR), Heidelberg University, Bergheimer Straße 20, 69115 Heidelberg, Germany; ${ }^{5}$ Division of Clinical Epidemiology and Aging Research, German Cancer Research Center (DKFZ), Im Neuenheimer Feld 581, 69120 Heidelberg, Germany; ${ }^{6}$ Nuffield Department of Primary Care Health Sciences, University of Oxford, Woodstock Rd, Oxford OX2 6GG, UK; ${ }^{7}$ Hellenic Health Foundation, 13 Kaisareias \& Alexandroupoleos, Athens 11527 , Greece; ${ }^{8}$ WHO Collaborating Center for Nutrition and Health, Unit of Nutritional Epidemiology and Nutrition in Public Health, Dept. of Hygiene, Epidemiology and Medical Statistics, Medical School, National and Kapodistrian University of Athens, Mikras Asias 75, Athens 115 27, Greece; ${ }^{9}$ Department Agrotechnology and Food Sciences, Division of Human Nutrition, Wageningen University, PO Box 17, 6700AA Wageningen, The Netherlands; ${ }^{10}$ Department of Epidemiology and Preventive Medicine, University of Regensburg, Franz-Josef-Strauß-Allee 11, 93053 Regensburg, Germany; ${ }^{11}$ Department of Hygiene and Epidemiology, University of loannina School of Medicine, University Campus, 45110 loannina, Greece; ${ }^{12}$ Department of Epidemiology and Biostatistics, The School of Public Health, Imperial College London, South Kensington Campus, London SW7 2AZ, UK; ${ }^{13}$ Danish Cancer Society Research Center, Strandboulevarden 49, DK 2100 Copenhagen $\varnothing$ Denmark; ${ }^{14}$ Icahn School of Medicine at Mount Sinai, 1 Gustave L. Levy Place, New York, NY 10029-5674, USA; ${ }^{15}$ Department for Determinants of Chronic Diseases (DCD), National Institute for Public Health and the Environment (RIVM), PO Box 1, 3720 BA Bilthoven, The Netherlands; ${ }^{16}$ Department of Social \& Preventive Medicine, Faculty of Medicine, University of Malaya, 50603 Kuala Lumpur, Malaysia; ${ }^{17}$ Department of Epidemiology, Murcia Regional Health Council, IMIB-Arrixaca, Ronda de Levante, 11, 30008, Murcia, Spain; ${ }^{18}$ CIBER Epidemiología y Salud Pública (CIBERESP), Melchor Fernández Almagro, 3-5, Madrid 28029, Spain; ${ }^{19}$ Division of Preventive Oncology, German Cancer Research Center (DKFZ) and National Center for Tumor Diseases (NCT), Im Neuenheimer Feld 581, 69120 Heidelberg, Germany; ${ }^{20}$ German Cancer Consortium (DKTK), German Cancer Research Center (DKFZ), Im Neuenheimer Feld 581, 69120 Heidelberg, Germany and ${ }^{21}$ Department of Community Medicine, UiT The Arctic University of Norway, 9037 Tromsø, Norway

Supplementary Information accompanies this paper on British Journal of Cancer website (http://www.nature.com/bjc) 